\title{
IDENTIFICACIÓN DE Pseudomonas fluorescens y Pseudomonas marginalis, CAUSANTES DEL SÍNDROME DE DESORDEN DEL PERIDERMO "PINK EYE" EN PAPA
}

\author{
Viteri, Analhí ${ }^{a *}$; Regalado, Hernando ${ }^{\text {b; }}$ Toaza, Alexander ${ }^{\text {b }}$ \\ a Universidad de las Américas (UDLA), De Los Colimes esq., Quito, Ecuador. \\ ${ }^{\mathrm{b}}$ Agencia de Regulación y Control Fito y Zoosanitario, Eloy Alfaro y Federico González Suárez. Av. \\ Interoceánica Km. 14 1/2, Sector La Granja del MAG, Quito, Ecuador.
}

Ingresado: 10/02/2020

\section{Resumen}

El síndrome de desorden del peridermo comúnmente conocido como pink eye, es una enfermedad que produce un deterioro en la superficie del tubérculo de Solanum tuberosum (papa) generando una pérdida de casi el 100\% del almidón. La sintomatología que presenta esta enfermedad es la pudrición acelerada, lesiones de textura acuosa, manchas negras en el tallo y puntos rosados en la superficie del tubérculo, causada por Pseudomonas fluorescens y Pseudomonas marginalis. Si bien P. fluorescens ha sido descrita como un eficiente controlador biológico, en Ecuador no ha sido reportada como agente patógeno en cultivos de papa. Ante las sospechas de síntomas relacionados con pink eye en zonas productoras, se planteó identificar su agente causal en plantas sintomáticas y asintomáticas en tres provincias del Ecuador. Se realizó un muestreo aleatorio en las provincias de Pichincha, Carchi y Chimborazo. Las muestras fueron inoculadas en medio B de King y luego de 48 horas de incubación se aislaron y purificaron veinte morfotipos coloniales de interés, de los cuales por reconocimiento visual a través de luz UV, pruebas bioquímicas tradicionales, sistema Biolog Inc y la secuenciación del gen 16S rRNA se identificaron siete aislados, dos como P. fluorescens y cinco como P. marginalis. Adicionalmente, se realizaron los postulados de Koch con $P$. fluorescens y $P$. marginalis en veinte tubérculos, diez para cada especie y se confirmó la patogenicidad que producen las dos bacterias por separado en $S$. tuberosum.

*Correspondencia a: Universidad de las Américas, De Los Colimes esq., Quito, Ecuador. Tel: 593995872183.

Correo electrónico: analhiviteri@gmail.com
Aceptado: 06/07/2020

Palabras clave: Pink eye, Postulados de Koch, Pseudomonas fluorescens, Pseudomonas marginalis, Solanum tuberosum.

\section{IDENTIFICATION OF Pseudomonas fluorescens and Pseudomonas marginalis, ASSOCIATED WITH "PINK EYE" PERIDERMAL DISORDER SYNDROME IN POTATO.}

\begin{abstract}
The syndrome of periderm disorder known as pink eye, is a disease that produces a disorder on the surface of the tuber of Solanum tuberosum (potato) generating a loss of almost $100 \%$ of the starch. The symptoms of this disease are accelerated rot, watery textured lesions and black spots on the stem and pink spots on the surface of the tube, caused by Pseudomonas fluorescens and Pseudomonas marginalis. Although P. fluorescens has been described as an efficient biological controller and in Ecuador it has not been reported as a pathogen in potato crops. Given the suspicions of symptoms related to pink eye in producing areas, it was proposed to identify its causative agent in symptomatic and asymptomatic plants in three provinces of Ecuador. A random sampling was carried out in the provinces of Pichincha, Carchi and Chimborazo. The samples were inoculated in King's B medium and after 48 hours of incubation twenty colonial morphotypes of interest were isolated and purified. By visual recognition through UV light, traditional biochemical tests, Biolog Inc system and 16S rRNA gene sequencing seven isolates were identified, two as $P$. fluorescens and five as $P$. marginalis. In addition, Koch's postulates were performed with $P$. fluorescens and $P$. marginalis in twenty tubers, ten for each species,
\end{abstract}


and the pathogenicity of the two bacteria in $S$. tuberosum was confirmed separately.

Keywords: Koch's postulates, Pink eye, Pseudomonas fluorescens, Pseudomonas marginalis, Solanum tuberosum.

\section{INTRODUCCIÓN}

El síndrome de desorden del peridermo comúnmente conocido como pink eye o conjuntivitis de la papa (Solanum tuberosum), es una alteración conocida por producir un deterioro del tubérculo en sus procesos de producción de precosecha, cosecha y postcosecha. Esta enfermedad es generada por la apoptosis o muerte celular programada de las células que pertenecen al felógeno o peridermo del tubérculo. La evidencia física que esta patología presenta es una destrucción en el peridermo y a su vez una coloración rosada en la superficie, áreas hinchadas o ásperas en la planta y pudrición del tallo o tubérculo con lesiones de textura acuosa [1]. La enfermedad ha sido relacionada con $P$. fluorescens desde el año 1959 en Maine, Estados Unidos, por los investigadores Folsom y Friedman, quienes descubrieron que podía generar graves alteraciones en la planta como los síntomas anteriormente descritos [2]. P. fluorescens es una bacteria Gram negativa, perteneciente a la clase Gammaproteobacteria, que ha sido descrita como endófita en diversas plantas, incluyendo aquellas de la familia Solanaceae y como saprófita en el suelo [3]. Aunque algunas investigaciones reportan la existencia de cepas eficientes como biocontroladoras [4], otros estudios la han descrito como una especie fitopatógena en determinados cultivos. Por ejemplo, P. fluorescens, se ha aislado del parénquima de algunas solanáceas enfermas como Solanum lycopersicum o Solanum melongena [5]. En conexión con esto, en el año 2000, el Departamento de Protección de Plantas en Riyadh Abha, Arabia Saudita, analizó las plantas de tomate (Solanum lycopersicum L.) con lesiones en los tallos, raíces adventicias y pudrición en el fruto, aislando P. fluorescens (biotipo I) como agente causal [6]. Asimismo, en los años 1999 y 2000 en Corea del Sur se descubrió que P. marginalis en conjunto con Pectobacterium sp. se asociaban a una alteración consistente en lesiones de raíces, tales como podredumbres blandas, oxidación y marchitamiento en bulbos de lirios [7]. Además, en estudios desarrollados en Nepal se determinó que $P$. marginalis es considerada como un fitopatógeno altamente perjudicial para el cultivo de papa, y también, es reconocida como una plaga que se encuentra alrededor del mundo, por lo cual ingresa en la lista de patógenos cuarentenarios [8].

La presente investigación se realizó debido a la escasez de información acerca de la patogenicidad de los dos microorganismos mencionados en el Ecuador, ya que $P$. fluorescens es utilizada como agente biológico certificado en varios países y se usa principalmente para regular la invasión de fitopatógenos [9]. Investigaciones realizadas sobre el síndrome de desorden del peridermo y sus principales causas, aún se encuentran en debate [10], se consideran estudios arcaicos o a su vez no demuestran la patogenicidad o su riesgo que posee $P$. fluorescens en solanáceas $[2,11]$. Asimismo, la enfermedad mencionada, solo ha sido identificada e investigada en Arabia Saudita y en Estados Unidos [12]. Sin embargo, según el Centro de Biociencia Agrícola Internacional (CABI, por sus siglas en inglés), que es el encargado de investigar problemas relacionados al medio ambiente y la agricultura para el conocimiento de plagas, diagnóstico, control y manejo de las mismas, la enfermedad está distribuida en varios países de Latinoamérica [13]. Finalmente, este patógeno podría afectar al agricultor de papa en el aspecto económico, dado que la tierra queda afectada, comprometiendo la viabilidad de próximos cultivos [14]. Por su parte P. marginalis, es una bacteria cuarentenaria que debe ser controlada de inmediato pues puede ocasionar la pérdida completa de la plantación, siendo necesaria su identificación temprana [15].

El objetivo de la presente investigación fue aislar e identificar, mediante técnicas bioquímicas y moleculares, $P$. fluorescens y $P$. marginalis en plantas de $S$. tuberosum, con la sintomatología del síndrome de desorden del peridermo, en tres provincias del territorio ecuatoriano.

\section{METODOLOGÍA}

Para el presente estudio, se recolectaron muestras de tubérculos a partir de plantas de papa variedad Súper Chola. Este procedimiento tuvo lugar en las provincias de Pichincha, Chimborazo y Carchi. En cada provincia se muestreó de dos a tres lotes por cantón, cada lote tenía un tamaño alreded or de 10.000 a $25.000 \mathrm{~m}^{2}$ y la distancia entre las plantas aproximadamente eran de cincuenta centímetros y entre surcos de 
un metro. El muestreo consistió en recolectar tubérculos de plantas muestreadas al azar con síntomas de afección bacteriana. Se estableció un estimado porcentual de severidad, relacionando tubérculos sintomáticos con tubérculos sanos, en función de la superficie de la plantación en cada una de las provincias [16], se observó que cada planta tenía alrededor de 10 tubérculos, lo que se consideró como una sola muestra. Los síntomas que se observaron en las plantas fueron manchas negras y rosadas, lesiones de textura acuosa y pudrición general. En las provincias de Pichincha, Chimborazo y Carchi, se recolectaron 18,30 y 11 muestras, respectivamente. Cada muestra fue registrada e identificada correctamente, acompañada con la etiqueta, se las colocó en papel toalla dentro de una funda plástica Ziploc y fueron transportadas en cajas térmicas, bajo condiciones de refrigeración hacia el Laboratorio de Fitopatología de la Agencia de Regulación y Control Fito y Zoosanitario - AGROCALIDAD, en donde se les asignó un código interno, (FP-19-), FP debido a las siglas del laboratorio, 19 por el año en el cual se realizó el estudio y el número secuencial generado por la base de datos para cada una de ellas. Posterior a su llegada al laboratorio, los tubérculos fueron lavados con agua potable para retirar el exceso de tierra, ulteriormente se cortaron las secciones de los tubérculos que presentaban sintomatología, y se les realizó un lavado de un minuto con hipoclorito de sodio al $2 \%$ con agitación, y finalmente tres lavados con agua destilada estéril para eliminar los residuos de hipoclorito de sodio.

\subsection{Materiales y métodos para la obtención de datos}

\subsubsection{Medios de Cultivo}

El medio de cultivo que se utilizó fue B de King Agar, en función de su capacidad selectiva para el crecimiento de Pseudomonas spp., además de estimular la producción natural de sideróforos, como piocianinas y pioverdinas, en éste género, lo que conduce a la formación de colonias fluorescentes bajo luz UV [17]. Esta característica diferencial fue utilizada como criterio de selección de las colonias que debían ser purificadas y caracterizadas como se describe posteriormente. El medio de cultivo fue preparado de acuerdo a las instrucciones del fabricante (DB Difco, Heidelberg, Alemania), esterilizado durante 15 minutos en autoclave a $121{ }^{\circ} \mathrm{C}$ y 15 libras de presión, para luego ser dispensado en cajas Petri estériles.

\subsubsection{Cultivo}

Se realizó una maceración de las secciones con sintomatología de las muestras de tubérculo y tallo con agua peptonada $0,1 \%(\mathrm{~m} / \mathrm{v})$ estéril. Esta suspensión fue diluida de forma seriada desde $10^{-1}$ hasta $10^{-3}$ en todas las muestras, y $100 \mu \mathrm{L}$ de la última dilución fueron inoculados en la superficie de placas de B de King Agar por triplicado. Estas fueron incubadas durante 48 horas a $26{ }^{\circ} \mathrm{C}$ y posteriormente las colonias que mostraron fluorescencia bajo luz UV, fueron seleccionadas y purificadas para ser subsecuentemente caracterizadas.

\subsubsection{Caracterización bioquímica de los aislamientos}

Cada uno de los aislamientos bacterianos fueron caracterizados mediante pruebas bioquímicas tradicionales, incluyendo pruebas de catalasa en que se utilizó peróxido de hidrógeno al $3 \%$ y se resuspendió en una gota de esta solución, y oxidasa se realizó de acuerdo a las instrucciones del fabricante (Becton, Dickinson and Company 7 Loveton Circle Sparks, MD, Estados Unidos), tinción Gram y observación microscópica. Además, se empleó el sistema Biolog Inc de caracterización fenotípica de alto rendimiento, basado en la generación de perfiles de consumo de fuentes de carbono. Para esto, se utilizaron microplacas GEN III que fueron inoculadas individualmente con suspensiones de los distintos aislamientos en el medio IF-A específicos para bacterias aerobias, [17] e incubadas durante 48 horas a $30{ }^{\circ} \mathrm{C}$. La lectura de cada uno de los perfiles generados fue realizada, cada 24 horas durante dos días, en el equipo Microstation Reader e interpretada por el programa informático MicroStation GEN III Data Collection Software mediante comparación con la base de datos GEN III.

\subsubsection{Conservación de los aislamientos}

Aquellos aislamientos cuyo perfil fenotípico fue compatible con Pseudomonas spp., fueron propagados en agar nutritivo, y a partir de colonias aisladas, suspendidos en caldo nutritivo suplementado con glicerol $20 \%$ (m/v), alcanzando una turbidez comparable con la del estándar McFarland 1 y criopreservados 
a $-80{ }^{\circ} \mathrm{C}$. Para los análisis posteriores, estos aislamientos criopreservados fueron reactivados al ser inoculados en agar nutritivo e incubados a $30^{\circ} \mathrm{C}$ durante 48 horas.

\subsubsection{Extracción de ADN}

Cada una de las cepas aisladas fue propagada, individualmente, en $10 \mathrm{~mL}$ de caldo nutritivo durante $24 \mathrm{~h}$ a $30{ }^{\circ} \mathrm{C}$. Se recolectaron $2 \mathrm{~mL}$ de esos cultivos en microtubos cónicos y se centrifugaron a $14000 \mathrm{rpm}$ por $10 \mathrm{~min}$. Se removió el sobrenadante y el sedimento fue resuspendido en $100 \mu \mathrm{L}$ en agua libre de DNasa y RNasa. Dicha suspensión fue incubada a $95{ }^{\circ} \mathrm{C}$ con agitación por 10 min y se centrifugó nuevamente. La concentración del ADN extraído fue determinada en función de la medición espectrofotométrica de la densidad óptica, en Nanodrop, a una longitud de onda de $260 \mathrm{~nm}$. La calidad del ADN extraído fue determinada en base a la relación 260/280 nm y 260/230 nm.

\subsubsection{Amplificación y electroforesis}

Un fragmento de $1461 \mathrm{pb}$ del gen $16 \mathrm{~S}$ rRNA fue amplificado mediante Reacción en Cadena de la Polimerasa (PCR por sus siglas en inglés). Para esto se utilizó el par de cebadores universales 27F (5'AGAGTTTGATCMTGGCTCAG3') y 1492R (5'ACCTTGTTACGACTT3') [18]. La mezcla de PCR, con un volumen final de $50 \mu \mathrm{L}$, consistió en $2 \mu \mathrm{L}$ de ADN molde y $48 \mu \mathrm{L}$ de Master mix Invitrogen ${ }^{\mathrm{TM}}$ que se distribuyeron de la siguiente manera: $40,25 \mu \mathrm{L}$ de $\mathrm{ddH}_{2} \mathrm{O}, 5 \mu \mathrm{L}$ de Buffer, 1,5 $\mu \mathrm{L}$ de $\mathrm{MgCl}_{2}, 0,5 \mu \mathrm{L}$ de dNTPs, $0,25 \mu \mathrm{L}$ de cada cebador, y 0,5 $\mu \mathrm{L}$ de Taq Polimerasa. La reacción de PCR comprendió una fase inicial de desnaturalización a $94{ }^{\circ} \mathrm{C}$ por 3 minutos, seguido de 35 ciclos de desnaturalización por 30 segundos a $95{ }^{\circ} \mathrm{C}$, alineamiento por 30 segundos a $50{ }^{\circ} \mathrm{C}$, elongación por 1 minuto a $72{ }^{\circ} \mathrm{C}$, y un paso final de extensión de 10 minutos a $72{ }^{\circ} \mathrm{C}$ [18]. Finalmente, los productos de PCR fueron separados mediante electroforesis en gel de agarosa $1,5 \%$, utilizando un voltaje de $110 \mathrm{~V}$ por $40 \mathrm{~min}$. La formación de bandas en el gel de agarosa fue revelada mediante tinción con Invitrogen ${ }^{\mathrm{TM}} \mathrm{SYBR}^{\mathrm{TM}} \mathrm{Safe}^{\mathrm{TM}}$ DNA Gel Stain. Con el propósito de determinar el tamaño (pb) de las bandas, se empleó el marcador molecular Low Mass Ladder de Invitrogen ${ }^{\text {TM }}$ de $2 \mathrm{~kb}$.

\subsubsection{Secuenciación e identificación}

Los productos de PCR de los siete aislados obtenidos de las tres provincias fueron secuenciados en Macrogen (Seúl, Corea del Sur) por el método de Sanger. Las secuencias nucleotídicas obtenidas por los iniciadores 27F (5'AGAGTTTGATCMTGGCTCAG3') y 1492R (5'ACCTTGTTACGACTT3') fueron comparadas con aquellas depositadas en Genbank, mediante la herramienta NCBI Blast, identificándose de esa manera el género y especie de los distintos aislamientos bacterianos.

\subsubsection{Postulados de Koch}

La concentración celular del inóculo se calculó mediante la determinación espectrofotométrica de la D.O. ( $\alpha 600 \mathrm{~nm})$ de suspensiones celulares de los distintos aislamientos, y se ajustó a una curva de crecimiento previamente realizada, estableciendo la relación entre D.O. y UFC (unidades formadoras de colonias) de cada especie [19]. Se hicieron diluciones seriadas de $10^{-1}$ a $10^{-7}$ en placas con medio B de King Agar por triplicado, se dejaron incubar a $26^{\circ} \mathrm{C}$ por 48 horas, y luego del período de crecimiento se examinaron las placas y se contaron aquellas que tuvieron entre 30 y 300 colonias [20]. Los inóculos utilizados en el ensayo se ajustaron a una concentración de $10^{8} \mathrm{UFC}^{*} \mathrm{~mL}^{-1}$ con solución salina estéril ( $\mathrm{NaCl}$ al 0,85\%) [19]. Se trabajó con dos aislados pertenecientes a las provincias de Pichincha y Carchi; P. fluorescens y $P$. marginalis, respectivamente. Se realizaron cámaras húmedas en dos recipientes plásticos, colocando algodones empapados de agua en los costados, y en el centro se dispusieron diez tubérculos de la variedad Súper Chola para cada tratamiento [21]. El primer tubérculo no fue inoculado y se lo consideró como testigo, el segundo fue inyectado con agua destilada estéril (control negativo), y a los ocho restantes se les inyectó $1 \mathrm{~mL}$ de la suspensión de cada especie en 12 puntos diferentes del tubérculo [21]. Estos especímenes se mantuvieron en condiciones de invernadero, con una temperatura de $28-30^{\circ} \mathrm{C}$ durante el día y en la noche de $19-21^{\circ} \mathrm{C}$ a una humedad relativa de $60 \%$. A los diez días después de la inoculación se observaron lesiones de pudrición interna 
en el tubérculo, pudrición en la zona externa y manchas negras en la superficie, a causa de que el tubérculo se empieza a podrir y pierde dureza.

\section{RESULTADOS Y DISCUSIÓN}

\subsection{Identificación de Pseudomonas} fluorescens y Pseudomonas marginalis en tubérculos de Solanum tuberosum (papa), en muestras de Pichincha, Carchi y Chimborazo

\subsubsection{Sintomatología}

La sintomatología que presentaron los tubérculos muestreados fueron manchas rosadas, negras y verdes en su superficie (Fig. 1A, Fig. 1B y Fig. 1C) respectivamente, malformaciones por el mal funcionamiento que existe en el peridermo (Fig. 1B y Fig. 1C), y una suavidad notable en la superficie a causa de que el tubérculo se empieza a podrir y pierde dureza (Fig. 1C).
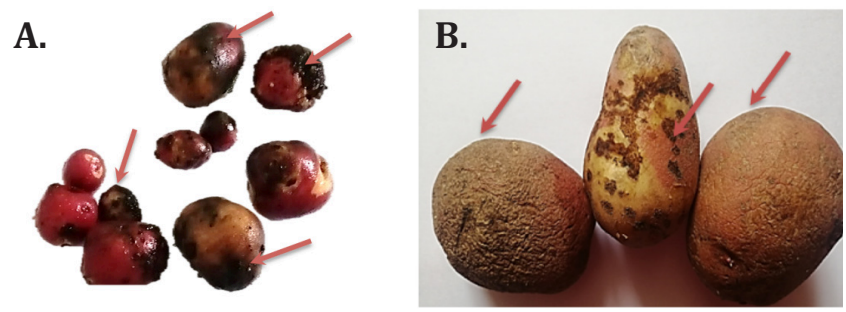

C.

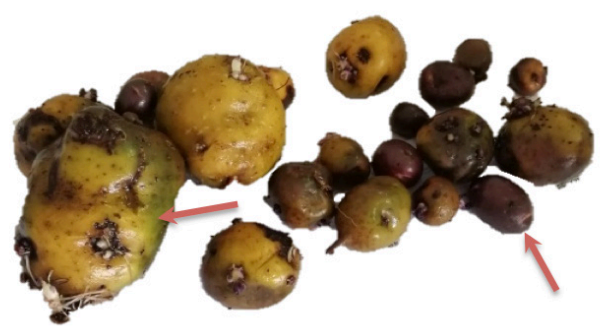

Fig.1: Muestras de tubérculos de las diferentes provincias con la sintomatología visible en su superficie como manchas rosadas, negras y verdes (A, B y C) respectivamente y malformaciones en la superficie (B y $\mathrm{C}$ ).

Según Folsom y Friedman [2], la sintomatología relacionada con el síndrome de desorden del peridermo como manchas negras, verdes, puntos rosados, pudrición interna y tallos con lesiones de textura acuosa, es realmente importante, debido a que se pueden identificar fisiológicamente las anomalías generadas por $P$. fluorescens y $P$. marginalis en la superficie de los tubérculos y en los tallos, síntomas que fueron compatibles con aquellos observados en las muestras recolectadas en las diferentes provincias muestreadas. Adicional a ello, Rodríguez [22] y Hernández [23] manifiestan que la enfermedad comienza con sintomatología similar a la de tubérculos en hojas y tallos, al transcurrir los diferentes estadíos de la planta, lo cual se pudo evidenciar en las muestras analizadas.

\subsubsection{Aislamiento en agar $B$ de King $y$ visualización mediante luz UV}

Como mecanismo de selección de P. fluorescens y $P$. marginalis se utilizó agar B de King. Las colonias de $P$. fluorescens produjeron un pigmento amarillo que rodeó la colonia, y que bajo condiciones de luz ultravioleta fue verde-amarillo fluorescente (Fig. 2A y Fig. 2B), mientras que $P$. marginalis bajo condiciones de luz ultravioleta fue azul fluorescente (Fig. 2A y Fig. 2C). Según McRose y colaboradores [24] establecieron en el año 2018, que las diferencias entre pigmentos pueden deberse al grado de patogenicidad, y consecuentemente al subgrupo que pertenezcan los microorganismos.
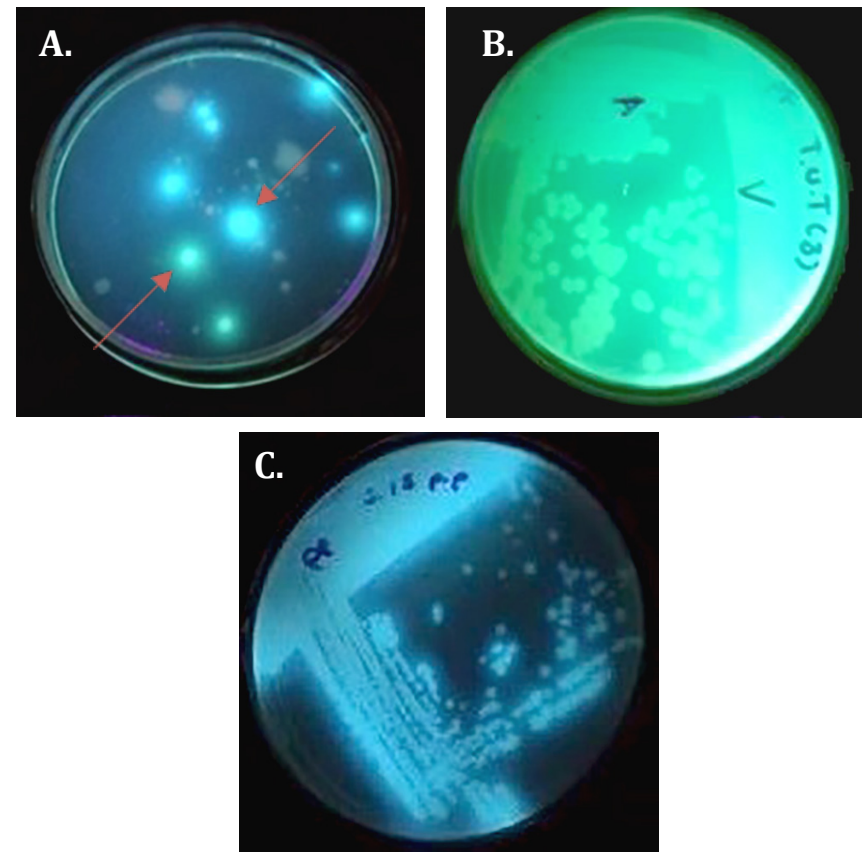

Fig.2: Aislamiento y purificación de Pseudomonas fluorescens y Pseudomonas marginalis. A) Crecimiento de bacterias aisladas de tubérculos de papa a las 48 horas de incubación en B de King Agar observadas bajo luz ultravioleta, B) Cultivo puro de $P$. fluorescens en B de King Agar observado bajo luz ultravioleta y C) Cultivo puro de P. marginalis en B de King Agar observado bajo luz ultravioleta. 


\subsubsection{Pruebas bioquímicas y pruebas BIOLOG de los aislados de Pseudomonas fluorescens y Pseudomonas marginalis}

La coloración Gram de cada una de las cepas en estudio reveló la presencia de un cultivo puro de bacilos alargados Gram negativos, propios de las especies de $P$. fluorescens y P. marginalis. La prueba para determinar la actividad del citocromo oxidasa resultó positiva, lo que se pudo evidenciar por el cambio de color azul en las tiras. En tanto que, la prueba de catalasa mostró producción de burbujas de gas, siendo positiva en todos los aislados. En las lecturas de las microplacas en Biolog de las muestras FP-19-0066, FP-19-0222, FP-19-0232, FP-
19-0244, FP-19-0577, FP-19-0577A y FP-190580 se obtuvieron los siguientes resultados: Pseudomonas fluorescens, Pseudomonas tolasii, Pseudomonas tolasii, Pseudomonas marginalis, Pseudomonas tolasii, Pseudomonas grimontii, Pseudomonas fluorescens, respectivamente, con valores SIM de 0.8 a 0.9 , que indica una gran similitud entre las especies analizadas con las de la base de datos. El valor SIM o índice de similitud determina la coincidencia entre el perfil metabólico analizado con el que se encuentra en la base de datos, y se requiere un valor SIM mayor que 0.5 para una coincidencia de especies [25]. Los resultados obtenidos de las 59 muestras analizadas se los puede observar en la Tabla 1.

Tabla 1. Resultados de las 59 muestras analizadas de las provincias de Pichincha, Carchi y Chimborazo.

\begin{tabular}{|c|c|c|c|c|c|c|}
\hline $\begin{array}{l}\text { NÚMERO DE } \\
\text { MUESTRA }\end{array}$ & PROVINCIA & $\begin{array}{c}\text { CÓDIGO DE } \\
\text { LA MUESTRA }\end{array}$ & $\begin{array}{c}\text { TINCIÓN } \\
\text { GRAM }\end{array}$ & CATALASA & OXIDASA & RESULTADO BIOLOG \\
\hline 1 & \multirow{18}{*}{ PICHINCHA } & FP-18-1561 & - & + & + & $\begin{array}{c}\text { Achromobacter } \\
\text { xylosoxidans }\end{array}$ \\
\hline 2 & & FP-18-1562 & + & + & - & Bacillus megaterium \\
\hline 3 & & FP-18-1563 & - & + & - & Klebsiella oxytoca \\
\hline 4 & & FP-18-1564 & - & + & - & Klebsiella pneumoniae \\
\hline 5 & & FP-19-0060 & - & + & + & $\begin{array}{c}\text { Achromobacter } \\
\text { xylosoxidans }\end{array}$ \\
\hline 6 & & FP-19-0061 & + & + & + & Micrococcus luteus \\
\hline 7 & & FP-19-0062 & - & + & - & Enterobacter cloacae \\
\hline 8 & & FP-19-0063 & - & + & - & Klebsiella oxytoca \\
\hline 9 & & FP-19-0064 & - & + & + & $\begin{array}{c}\text { Achromobacter } \\
\text { xylosoxidans }\end{array}$ \\
\hline 10 & & FP-19-0065 & + & + & + & Micrococcus luteus \\
\hline 11 & & FP-19-0066 & - & + & + & $\begin{array}{l}\text { Pseudomonas } \\
\text { fluorescens }\end{array}$ \\
\hline 12 & & FP-19-0067 & - & + & - & Klebsiella pneumoniae \\
\hline 13 & & FP-19-0068 & - & + & - & Klebsiella oxytoca \\
\hline 14 & & FP-19-0091 & - & + & + & $\begin{array}{l}\text { Achromobacter } \\
\text { xylosoxidans }\end{array}$ \\
\hline 15 & & FP-19-0092 & - & + & + & $\begin{array}{l}\text { Achromobacter } \\
\text { xylosoxidans }\end{array}$ \\
\hline 16 & & FP-19-0093 & + & + & - & $\begin{array}{l}\text { Bacillus subtilis ss } \\
\text { subtilis }\end{array}$ \\
\hline 17 & & FP-19-0094 & + & + & + & Micrococcus luteus \\
\hline 18 & & FP-19-0095 & - & + & - & Klebsiella oxytoca \\
\hline 19 & \multirow{4}{*}{ CARCHI } & FP-19-0222 & - & + & + & Pseudomonas tolasii \\
\hline 20 & & FP-19-0223 & - & + & - & Klebsiella oxytoca \\
\hline 21 & & FP-19-0224 & - & + & - & Klebsiella pneumoniae \\
\hline 22 & & FP-19-0227 & - & + & - & Klebsiella oxytoca \\
\hline
\end{tabular}




\begin{tabular}{|c|c|c|c|c|c|c|}
\hline 23 & \multirow{7}{*}{ CARCHI } & FP-19-0228 & - & + & - & Klebsiella oxytoca \\
\hline 24 & & FP-19-0232 & - & + & + & Pseudomonas tolasii \\
\hline 25 & & FP-19-0233 & + & + & - & $\begin{array}{c}\text { Bacillus subtilis ss } \\
\text { subtilis }\end{array}$ \\
\hline 26 & & FP-19-0234 & - & + & + & Burkholderia cepacia \\
\hline 27 & & FP-19-0237 & + & + & - & $\begin{array}{l}\text { Bacillus subtilis ss } \\
\text { subtilis }\end{array}$ \\
\hline 28 & & FP-19-0244 & - & + & + & $\begin{array}{l}\text { Pseudomonas } \\
\text { marginalis }\end{array}$ \\
\hline 29 & & FP-19-0247 & - & + & - & Kluyvera ascorbata \\
\hline 30 & \multirow{30}{*}{ CHIMBORAZO } & FP-19-0561 & - & + & - & Klebsiella oxytoca \\
\hline 31 & & FP-19-0562 & - & + & + & $\begin{array}{l}\text { Achromobacter } \\
\text { xylosoxidans }\end{array}$ \\
\hline 32 & & FP-19-0562 & + & + & + & Micrococcus luteus \\
\hline 33 & & FP-19-0563 & - & + & + & $\begin{array}{l}\text { Achromobacter } \\
\text { xylosoxidans }\end{array}$ \\
\hline 34 & & FP-19-0564 & - & + & + & $\begin{array}{l}\text { Achromobacter } \\
\text { xylosoxidans }\end{array}$ \\
\hline 35 & & FP-19-0565 & + & + & + & Micrococcus luteus \\
\hline 36 & & FP-19-0566 & - & + & - & Klebsiella oxytoca \\
\hline 37 & & FP-19-0567 & - & + & - & Klebsiella pneumoniae \\
\hline 38 & & FP-19-0568 & - & + & + & $\begin{array}{c}\text { Achromobacter } \\
\text { xylosoxidans }\end{array}$ \\
\hline 39 & & FP-19-0569 & + & + & + & Micrococcus luteus \\
\hline 40 & & FP-19-0570 & - & + & + & $\begin{array}{c}\text { Achromobacter } \\
\text { xylosoxidans }\end{array}$ \\
\hline 41 & & FP-19-0571 & - & + & - & Klebsiella pneumoniae \\
\hline 42 & & FP-19-0572 & - & + & - & Klebsiella oxytoca \\
\hline 43 & & FP-19-0573 & - & + & + & $\begin{array}{l}\text { Achromobacter } \\
\text { xylosoxidans }\end{array}$ \\
\hline 44 & & FP-19-0574 & + & + & - & Bacillus megaterium \\
\hline 45 & & FP-19-0575 & + & + & + & Micrococcus luteus \\
\hline 46 & & FP-19-0576 & - & + & + & Burkholderia cepacia \\
\hline 47 & & FP-19-0577 & - & + & + & Pseudomonas tolasii \\
\hline 48 & & FP-19-0577 A & - & + & + & $\begin{array}{c}\text { Pseudomonas } \\
\text { grimontii }\end{array}$ \\
\hline 49 & & FP-19-0578 & + & + & - & $\begin{array}{c}\text { Bacillus } \\
\text { amyloliquefaciens }\end{array}$ \\
\hline 50 & & FP-19-0579 & - & + & - & Klebsiella pneumoniae \\
\hline 51 & & FP-19-0580 & - & + & + & $\begin{array}{l}\text { Pseudomonas } \\
\text { fluorescens }\end{array}$ \\
\hline 52 & & FP-19-0581 & + & + & + & Micrococcus luteus \\
\hline 53 & & FP-19-0582 & - & + & - & Klebsiella oxytoca \\
\hline 54 & & FP-19-0583 & - & + & - & Klebsiella pneumoniae \\
\hline 55 & & FP-19-0584 & - & + & + & $\begin{array}{l}\text { Achromobacter } \\
\text { xylosoxidans }\end{array}$ \\
\hline 56 & & FP-19-0585 & - & + & + & $\begin{array}{c}\text { Achromobacter } \\
\text { xylosoxidans }\end{array}$ \\
\hline 57 & & FP-19-0586 & + & + & + & Micrococcus luteus \\
\hline 58 & & FP-19-0587 & - & + & - & Klebsiella oxytoca \\
\hline 59 & & FP-19-0588 & - & + & - & Klebsiella pneumoniae \\
\hline
\end{tabular}


3.1.4. Electroforesis, secuenciación e identificación de Pseudomonas fluorescens y Pseudomonas marginalis

La electroforesis en gel de agarosa reveló la presencia de productos de PCR de aproximadamente $1400 \mathrm{pb}$ (Fig. 3), lo que fue compatible con la región amplificada del gen $16 \mathrm{~S}$ rRNA. Entre las secuencias analizadas, cinco mostraron una similitud superior al 97\% con P. marginalis y dos con P. fluorescens (Tabla 2). La secuenciación del gen 16S rRNA como "barcode" universal, complementado por una caracterización fenotípica previa, brindó resultados decisivos por cuanto posee subregiones altamente conservadas, así como regiones hipervariables eficaces que conducen a una identificación rigurosa de procariotas [9].

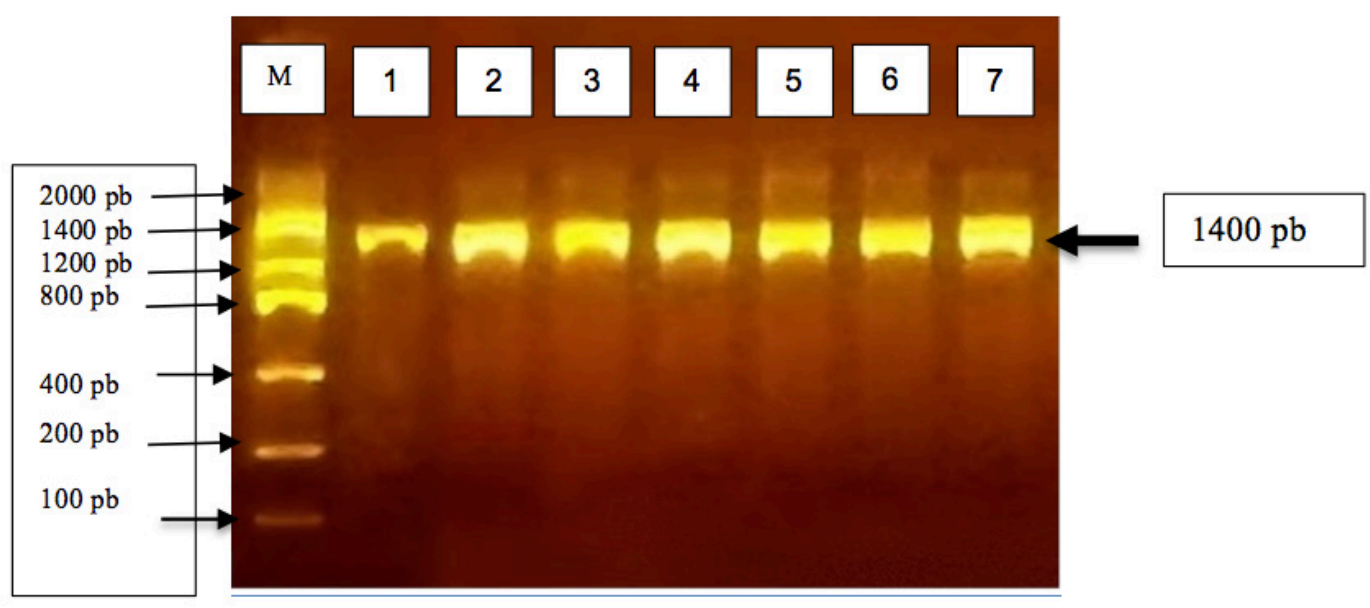

Fig.3: Electroforesis en gel de agarosa 1,5\% de la amplificación del gen 16S rRNA. M: marcador Low Mass Ladder (Invitrogen ${ }^{\mathrm{TM}}$ ). Carriles del 1 al 7 las muestras: FP-19-0066, FP-19-0222, FP-19-0232, FP-19-0244, FP-19-0577, FP-19-0577A y FP-19-0580.

Tabla 2. Resultados de las secuencias de P. fluorescens y P. marginalis.

\begin{tabular}{|c|c|c|c|c|}
\hline \multirow{2}{*}{ PROVINCIA } & CÓDIGO & ESPECIE & $\begin{array}{c}\text { PORCENTAJE DE } \\
\text { SIMILITUD }\end{array}$ & $\begin{array}{c}\text { NÚMERO DE ACCESO } \\
\text { AL GENBANK }\end{array}$ \\
\hline \multirow{2}{*}{ PICHINCHA } & FP-19-0066 & Pseudomonas fluorescens & $99.64 \%$ & NR_113647.1 \\
\hline \multirow{2}{*}{ CARCHI } & FP-19-0222 & Pseudomonas marginalis & $97.92 \%$ & NR_117821.1 \\
\cline { 2 - 5 } & FP-19-0232 & Pseudomonas marginalis & $98.96 \%$ & NR_117821.1 \\
\cline { 2 - 5 } & FP-19-0244 & Pseudomonas marginalis & $99.98 \%$ & NR_117821.1 \\
\hline \multirow{2}{*}{ CHIMBORAZ0 } & FP-19-0577A & Pseudomonas marginalis & $98.65 \%$ & NR_112072.1 \\
\cline { 2 - 5 } & FP-19-0580 & Pseudomonas fluorescens & $98.10 \%$ & NR_027230.1 \\
\cline { 2 - 5 } & Fseudomonas marginalis & $99.01 \%$ & NR_113647.1 \\
\hline
\end{tabular}

*Número de acceso en Genbank corresponde a aquel con el que la secuencia de cada uno de los aislamientos obtuvo el porcentaje de similitud indicado. 
Las secuencias de los distintos aislamientos identificados fueron ingresadas con los siguientes números de acceso al Genbank (Tabla $3)$.

Tabla 3. Número de acceso en Genbank de las secuencias del gen 16S rRNA correspondientes a las bacterias aisladas en el presente estudio.

\begin{tabular}{|l|l|c|}
\hline CÓDIGO & ESPECIE & $\begin{array}{c}\text { NÚMERO DE ACCESO } \\
\text { AL GENBANK }\end{array}$ \\
\hline FP-19-0066 & Pseudomonas fluorescens & MT579310 \\
\hline FP-19-0222 & Pseudomonas marginalis & MT579301 \\
\hline FP-19-0232 & Pseudomonas marginalis & MT573532 \\
\hline FP-19-0244 & Pseudomonas marginalis & MT579307 \\
\hline FP-19-0577 & Pseudomonas marginalis & MT579308 \\
\hline FP-19-0577A & Pseudomonas marginalis & MT582541 \\
\hline FP-19-0580 & Pseudomonas fluorescens & MT582528 \\
\hline
\end{tabular}

\subsubsection{Postulados de Koch}

Las dos bacterias con las cuales se trabajó las pruebas de patogenicidad $P$. fluorescens y $P$. marginalis fueron inoculadas en los tubérculos de papa, variedad Súper Chola, observándose a los diez días la sintomatología que causaban. P. fluorescens mostró lesiones de pudrición interna en el tubérculo, con la pérdida total del almidón, mientras que $P$. marginalis ocasionó una pudrición en la zona externa y manchas negras en la superficie, a causa de que el tubérculo se empieza a podrir y pierde dureza, al realizarse el corte del tubérculo se pudo observar que no existía una pérdida total del almidón, a diferencia de la lesión ocasionada por P. fluorescens (Fig. 4 y Fig. 5).
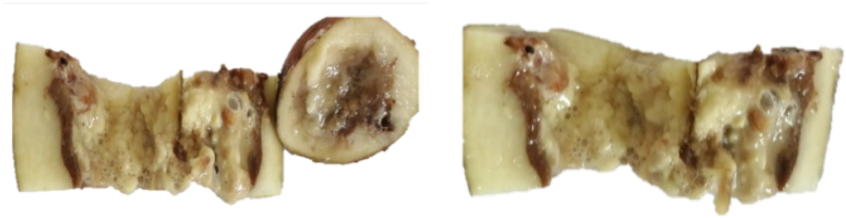

Fig. 4: Síntomas ocasionados por Pseudomonas fluorescens al décimo día de inoculación.
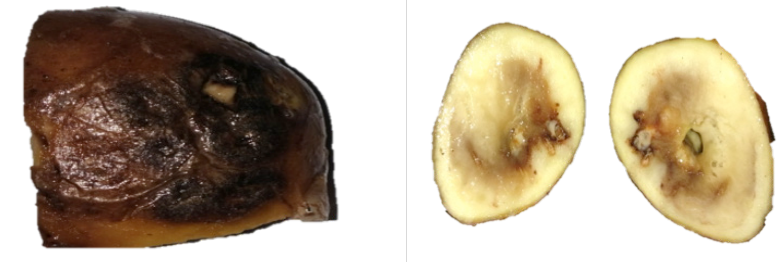

Fig. 5: Síntomas ocasionados por Pseudomonas marginalis al décimo día de inoculación.

La pudrición que se presenta en los tubérculos está relacionada con las exoenzimas, capaces de degradar componentes de la pared celular de plantas vasculares y otros componentes celulares [26], tienen un papel importante en enfermedades bacterianas como las podredumbres y necrosis [27].

A las bacterias nuevamente aisladas de las lesiones producidas en los tubérculos inoculados, se las identificó mediante secuenciación, confirmándose que eran $P$. fluorescens y P. marginalis (Tabla 4).

Tabla 4. Secuenciación de P.fluorescens y P. marginalis inoculadas en tubérculos sanos.

\begin{tabular}{|c|l|c|c|}
\hline CÓDIGO & ESPECIE & $\begin{array}{c}\text { PORCENTAJE } \\
\text { DE } \\
\text { SIMILITUD }\end{array}$ & $\begin{array}{c}\text { NÚMERO DE } \\
\text { ACCESO } \\
\text { AL GENBANK }\end{array}$ \\
\hline FP-19-0066 & $\begin{array}{l}\text { Pseudomonas } \\
\text { fluorescens }\end{array}$ & $99.64 \%$ & MT583078 \\
\hline FP-19-0244 & $\begin{array}{l}\text { Pseudomonas } \\
\text { marginalis }\end{array}$ & $99.98 \%$ & MT583077 \\
\hline
\end{tabular}

\section{CONCLUSIONES}

Mediante el empleo de pruebas bioquímicas convencionales, pruebas Biolog, moleculares y de patogenicidad, se comprobó que el síndrome de desorden del peridermo o comúnmente conocido como pink eye, fue ocasionado por las bacterias $P$. fluorescens y $P$. marginalis en cultivos de papa de las provincias de Pichincha, Carchi y Chimborazo.

La metodología utilizada, basada en una caracterización fenotípica en Biolog seguida de la secuenciación del gen $16 \mathrm{~S}$ rRNA, condujeron 
a los presentes resultados que se consideran confiables en función de los criterios de identificación en las bases de datos.

Pseudomonas fluorescens mostró lesiones de pérdida total del almidón, mientras que Pseudomonas marginalis no presentó ese tipo de sintomatología en los tubérculos.

\section{AGRADECIMIENTOS}

Al Laboratorio de Fitopatología y de Biología Molecular de la Agencia de Regulación y Control Fito y Zoosanitario - AGROCALIDAD Tumbaco, por todos los servicios prestados.

\section{REFERENCIAS}

[1] Zitter TA. Pinkeye of Potato in 2011-The Most Significant Appearance of This Disorder in 4 years [Internet]. [acesso 19 de febrero del 2019]. Disponible en: http://nrcc.cornell.edu/ climate/ithaca/moncrt_04-11.html

[2] Folsom D, Friedman BA. Pseudomonas fluorescens in relation to certain diseases of potato tubers in Maine. Am Potato J. 1959;36(3):90-7.

[3] Órgano Internacional de Difusión de la Sociedad Mexicana de

Fitopatología AC. REVISTA MEXICANA DE FITOPATOLOGÍA MEXICAN JOURNAL OF

PHYTOPATHOLOGY. 2018 Jan [accesso el 25 de abril del 2020];195.

Disponible en: https://www.smf.org.mx/rmf/ Contenido_Vol_38_2_2020.html

[4] Großkinsky DK, Tafner R, Moreno M V, Stenglein SA, De Salamone IEG, Nelson LM, et al. Cytokinin production by Pseudomonas fluorescens G20-18 determines biocontrol activity against Pseudomonas syringae in Arabidopsis. Sci Rep. 2016;6(1):1-11.

[5] Huether JP, McIntyre GA. Pectic enzyme production by two strains of Pseudomonas fluorescens associated with the pinkeye disease of potato tubers. Am Potato J. 1969; 46(11):41423.

[6] Al-Dhabaan FAM, Bakhali AH. Analysis of the bacterial strains using Biolog plates in the contaminated soil from Riyadh community. Saudi J Biol Sci. 2017;24(4):901-6.

[7] Li W, Ten LN, Kim S-H, Lee S-Y, Jung H-Y.
Occurrence of Bacterial Stem Rot of Ranunculus asiaticus Caused by Pseudomonas marginalis in Korea. Res Plant Dis [Internet]. 2018 Jun [acceso el 9 de abril del 2019]; 24(2):13844. Disponible en: http://www.koreascience.or.kr/article/ JAKO201820765438128.view

[8] Discovery Life. Pseudomonas marginalis Marginal leaf spot -- Discover Life [Internet]. 2017 [acceso el 27 de mayo del 2019]. Disponible en: https//www.discoverlife.org/ $\mathrm{mp} / 20 \mathrm{q}$ ? search $=$ Pseudomonas + marginalis \& flags $=$ glean

[9] Garrido-Sanz D, Meier-Kolthoff JP, Göker M, Martín M, Rivilla R, Redondo-Nieto M. Genomic and genetic diversity within the Pseudomonas fluoresces complex. PLoS One. 2016 Feb;11(2).

[10] Lulai EC, Sabba RP, Nolte P, Gudmestad NC, Secor GA. Periderm Disorder Syndrome: a New Name for the Syndrome For Formerly Referred to as Pink Eye. Am J Potato Res. 2018.

[11] KIBRIA G. Pesticides and Its Impact on Environment, Biodiversity and Human HealthA Short Review [Internet]. ResearchGate; 2016 [acesso el 27 de mayo del 2019]. Disponible en: https://www.academia.edu/27550948/ Pesticides_and_Its_Impact_on_Environment_ Biodiversity_and_Human_Health-_A_Short_ Review

[12] Lulai EC, Weiland JJ, Suttle JC, Sabba RP, Bussan AJ. Pink Eye Is an Unusual Periderm Disorder Characterized by Aberrant Suberization: A Cytological Analysis. Vol. 83, Amer J of Potato Res. 2006.

[13] CABI. Pseudomonas fluorescens (pink eye: potato) [Internet]. [acesso el 26 de octubre del 2018]. Disponible en: https://www.cabi.org/ isc/datasheet/44956

[14] Pascual JA, Moreno J, Ros M, Vargas M del C. Aspectos biológicos de la estabilización aeróbica II. 1. Mundi-Prensa; 2015.320p.

[15] Mahto BN. Generic Pest Risk Analysis for Potato in Nepal. J Nepal Agric Res Counc [Internet]. 2017 May [acceso el 9 de abril del 2019];3:32-7. Disponible en: https://doi. org/10.3126/jnarc.v3i1.17273

[16] Salazar D, Cuichán M, Ballesteros C, Márquez J, Orbe D. Encuesta de Superficie y Producción Agropecuaria Continua [Internet]. 2017 [accesso el 27 de mayo del 2019].

Disponible en: http://www.ecuadorencifras. gob.ec/documentos/web-inec/Estadisticas_ 
agropecuarias/espac/espac_2017/Informe_ Ejecutivo_ESPAC_2017.pdf

[17] Sasirekha B, Srividya S. Siderophore production by Pseudomonas aeruginosa FP6, a biocontrol strain for Rhizoctonia solani and Colletotrichum gloeosporioides causing diseases in chilli. Agric Nat Resour. 2016;50(4):250-6.

[18] Chen YL, Lee CC, Lin YL, Yin KM, Ho CL, Liu T. Obtaining long $16 \mathrm{~S}$ rDNA sequences using multiple primers and its application on dioxincontaining samples. BMC Bioinformatics. 2015 Dec;16(18):S13.

[19] Ozturk M, Eroglu Z, Secgin Z. First report of Xanthomonas campestris pv. campestris as the causal agent of black rot disease on red cabbage in Turkey. J Plant Pathol. 2019 Aug;101(3):795. [20] Keenleyside W. 9.2 How Microbes Grow [Internet]. Pressbooks; 2019 [acceso el 25 de junio del 2020]. Disponible en: https:// ecampusontario.pressbooks.pub/microbio/ chapter/how-microbes-grow/

[21] Departamento de Fitopatologia y Nematologia. Inoculação: Finalidade de Testes de patogenicidade. 2015.

[22] Rodríguez-Pérez C, Gómez-Caravaca AM, Guerra-Hernández E, Cerretani L, GarcíaVillanova B, Verardo V. Comprehensive metabolite profiling of Solanum tuberosum L. (potato) leaves by HPLC-ESI-QTOF-MS. Food Res Int [Internet]. 2018;112:390-9.

[23] Hernández-León R, Rojas-Solís D, Contreras-Pérez $\mathrm{M}$, Orozco-Mosqueda $\mathrm{M}$ del C, Macías-Rodríguez LI, Reyes-de la Cruz H, et al. Characterization of the antifungal and plant growth-promoting effects of diffusible and volatile organic compounds produced by Pseudomonas fluorescens strains. Biol Control. 2015;81:83-92.

[24] McRose DL, Seyedsayamdost MR, Morel FMM. Multiple siderophores: bug or feature? JBIC J Biol Inorg Chem [Internet]. 2018 Oct 27 [accesso 4 de abril del 2019];23(7):98393. Disponible en: http://link.springer. com/10.1007/s00775-018-1617-x

[25] Automated Microbial Identification and Quantitation: Technologies for the 2000s - Google Libros [Internet]. [accesso el 9 de abril del 2020]. Disponible en: https:// books. google. com.ec/ books?id=ez03IBf2YbgC\&pg= PA25\&lpg $=$ PA25\& dq $=$ val $d q=$ values + SIM + BIOLOG\&source =bl\&ots=pfTqoReAzN\&sig=
ACfU3U0A5VmE9ukH05Jk30DVki6Fh WnRFg WnRFg \& hl=es419\&sa=X\&ved=2ahUKEwiNg6D szvXpAhVkRN8KGdNjBE4Q6 AEwAHoECAkQA $\mathrm{Q} \# \mathrm{v}=$ onepa ge\& $\mathrm{q}=$ vge $\& \mathrm{q}=$ val ues SIM BIOLOG\&f $=$ false

[26] Nefzi A, Aydi Ben Abdallah R, JabnounKhiareddine $\mathrm{H}$, Ammar N, MedimaghSaïdana S, Haouala R, et al. Management of Fusarium Crown and Root Rot of tomato by Solanum linnaeanum L. extracts. Sci Hortic (Amsterdam).2018;238:204-14.

[27] Al-Mughrabi KI. Biological control of Fusarium dry rot and other potato tuber diseases using Pseudomonas fluorescens and Enterobacter cloacae. Biol Control. 2010;53(3):280-4. 